\title{
Flame Spread on Charring Materials: Numerical Predictions and Critical Conditions
}

\author{
MICHAEL A. DELICHATSIOS and YONGGANG CHEN \\ Factory Mutual Research Corporation \\ Norwood, MA 02062, USA
}

\section{ABSTRACT}

A detailed flame spread computer code has been applied to predicting flame spread and fire growth for the upward wall orientation on charring materials. The flammability properties for the pyrolysis rate of charring materials have been measured by performing pyrolysis experiments and surface temperature measurements in inert atmospheres. An extensively validated integral pyrolysis model for charring materials was employed in a flame spread code: the present flame spread code is an improvement and modification of a code presented in a previous paper. The improvements include:

a) calculation of the burnout front,

b) incorporation of convective heat loss from the front and back surface and

c) profiles for the heat flux distribution from the flame to the wall.

The flame spread code can also routinely handle preheating of the wall by externally imposed heat fluxes prior to ignition. Predictions from the model are compared with various experiments for upward flame spread performed at NIST and in Japan; the agreement is good. In addition, the model and the experiments verify that flame spread stops when the flame height is nearly equal to the length of pyrolysis region. This maximum flame spread length is simply related to the properties of the charring material as $\overline{\mathrm{L}}_{\mathrm{m}} \sim\left(\dot{\mathrm{q}}_{\mathrm{ne}}^{\prime \prime} \chi_{\mathrm{A}}\right.$ $\left.\Delta \mathrm{H}_{c} /\left(\Delta \mathrm{H}_{\mathrm{v}}\right)_{\mathrm{cff}}\right)^{2}$ where $\dot{\mathrm{q}}_{\mathrm{nct}}^{\prime \prime}$ is the net heat flux from the flames (equal to flame heat flux minus reradiation losses at the pyrolysis temperature), $\chi_{\mathrm{A}} \bullet \Delta \mathrm{H}_{\mathrm{c}}$ is the actual heat of combustion and $\left(\Delta \mathrm{H}_{\mathrm{v}}\right)_{\text {eff }}$ is the heat of gasification of the material corrected for char conductivity effects.

KEYWORDS: Numerical Predictions, Charring Material, Flame Spread

\section{INTRODUCTION}

Flame spread and growth on a material are determined by the thermal response of the material to an imposed heat flux distribution from its own flames or the environment. The thermal response of a material includes its preheating up to a pyrolysis or ignition temperature as well as its mass pyrolysis rate and the burning properties of pyrolyzing gases. Combustion of the pyrolyzing gases provides the radiative and convective heat flux back to the material as well as the products of combustion. How all these parameters are combined to affect flame spread rates depends also on the flame geometry and scale.

We have combined all these components in a flame spread and growth code (FSG) which has been applied to upward flame spread on non-charring materials such as PMMA ${ }^{1,2}$

In this work, we apply the flame spread code for classifying and predicting fire spread and growth rates in a vertical wall situation for charring materials such as (Douglas Fir) particle board ${ }^{3,4}$. Without doubt an important impetus for this application has been the 
development of a) a methodology for obtaining pyrolysis properties for charring materials $\mathbf{s}^{3,5}$ and b) a numerical model for the pyrolysis rates of charring materials ${ }^{3,5}$. This numerical program for the transient pyrolysis of charring materials has been inserted into a flame spread and growth (FSG) code ${ }^{1}$ which includes consideration of wall material burnout.

\section{PYROLYSIS RATES FOR CHARRING MATERIALS: NUMERICAL MODELING}

Figure 1 shows an application of the numerical pyrolysis model used for predicting pyrolysis rates of a charring material which is (Douglas Fir) Particle Board (19 mm thick) exposed to a heat flux of $5.83 \mathrm{~W} / \mathrm{cm}^{2}$.

The methodology for obtaining the solid material ${ }^{3,5}$ properties consists of two parts 1) the virgin material properties $\left(\mathrm{k}_{\mathrm{v}}, \rho_{\mathrm{v}}, \mathrm{c}_{\mathrm{v}}, \mathrm{T}_{\mathrm{p}}\right)$ are deduced from measurements of surface temperature and/or ignition time $\left.{ }^{3,5} 2\right)$ the charring properties $\left(k_{c}, \rho_{c}, c_{c}\right.$, heat of gasification )are deduced from mass loss and/or surface temperature histories ${ }^{5}$.

For the (Douglas Fir) particle board of Figure 1, its properties ${ }^{3,5}$ were obtained from data at an imposed heat flux of $3.55 \mathrm{~W} / \mathrm{cm}^{2}$; then, these properties were used to make the

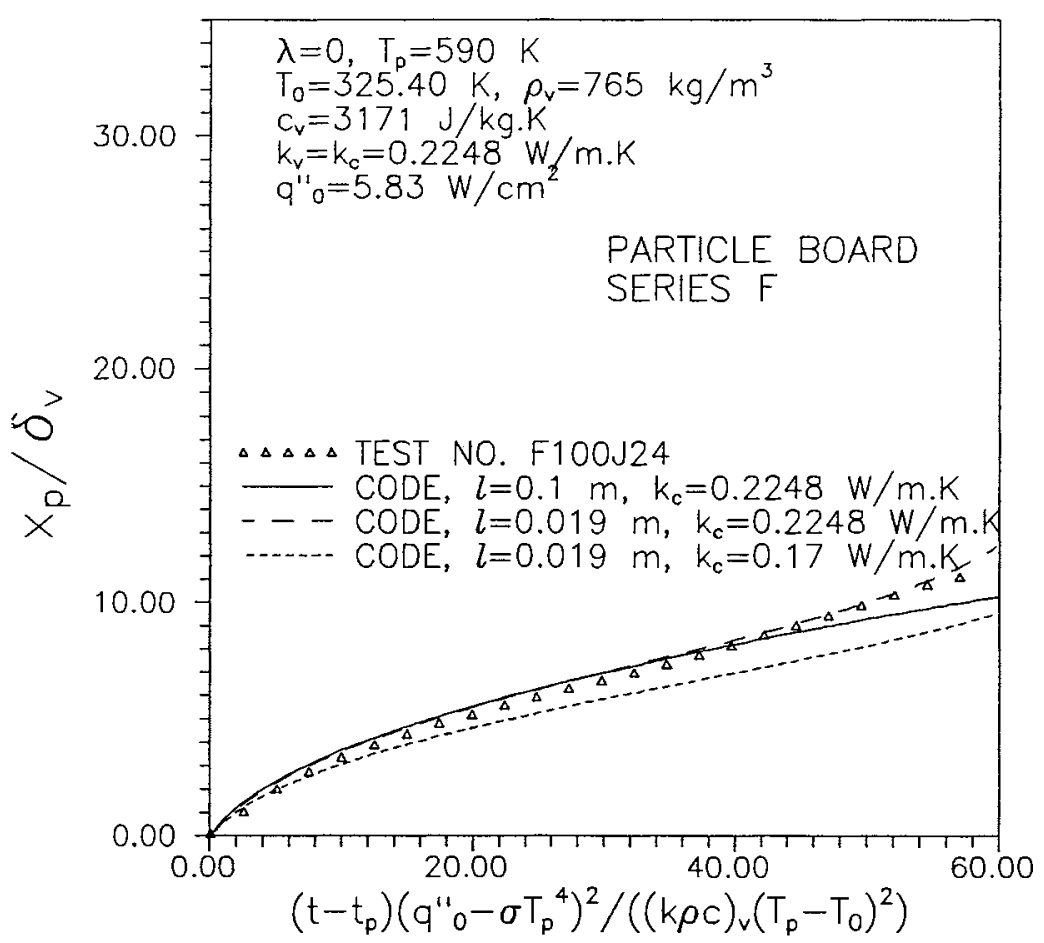

Figure 1 An illustration of the methodology for obtaining material properties needed for predicting mass pyrolysis histories. 
predictions shown in Fig. 1 for an imposed heat flux of $5.83 \mathrm{~W} / \mathrm{cm}^{2}$ wherein the importance of the finite thickness of the material $(19 \mathrm{~mm})$ is also demonstrated. This Figure shows that using the properties deduced for particle board, one can predict the effects of finite thickness $(l=0.019 \mathrm{~m}$ ) which can result in an increase in the pyrolysis rate (see later times in Fig. 1) because of decreased conduction losses as the thermal layer reaches the insulated back surface.

\section{UPWARD FLAME SPREAD EXPERIMENTS ON A PARTICLE BOARD SLAB BY SAITO ET. AL. ${ }^{4}$}

The pyrolysis model for charring materials has been incorporated into FMRC's Upward Flame Spread and Growth code ${ }^{\mathfrak{l}}$. This development together with the determination of charring material flammability properties has allowed predictions which can be compared with experiments. Such experiments on (Douglas Fir) particle board have been reported by Saito et. al. ${ }^{4}$ Vertical particle board slabs $30 \mathrm{~cm}$ wide by $13 \mathrm{~mm}$ thick were ignited by a methane line bumer having the same width as the particle board slabs. The bumer power could be varied from $18 \mathrm{~kW} / \mathrm{m}$ to about $100 \mathrm{~kW} / \mathrm{m}$. The pyrolysis front was determined from surface temperature measurements along the sample vertical centerline and the flame heights were determined visually.

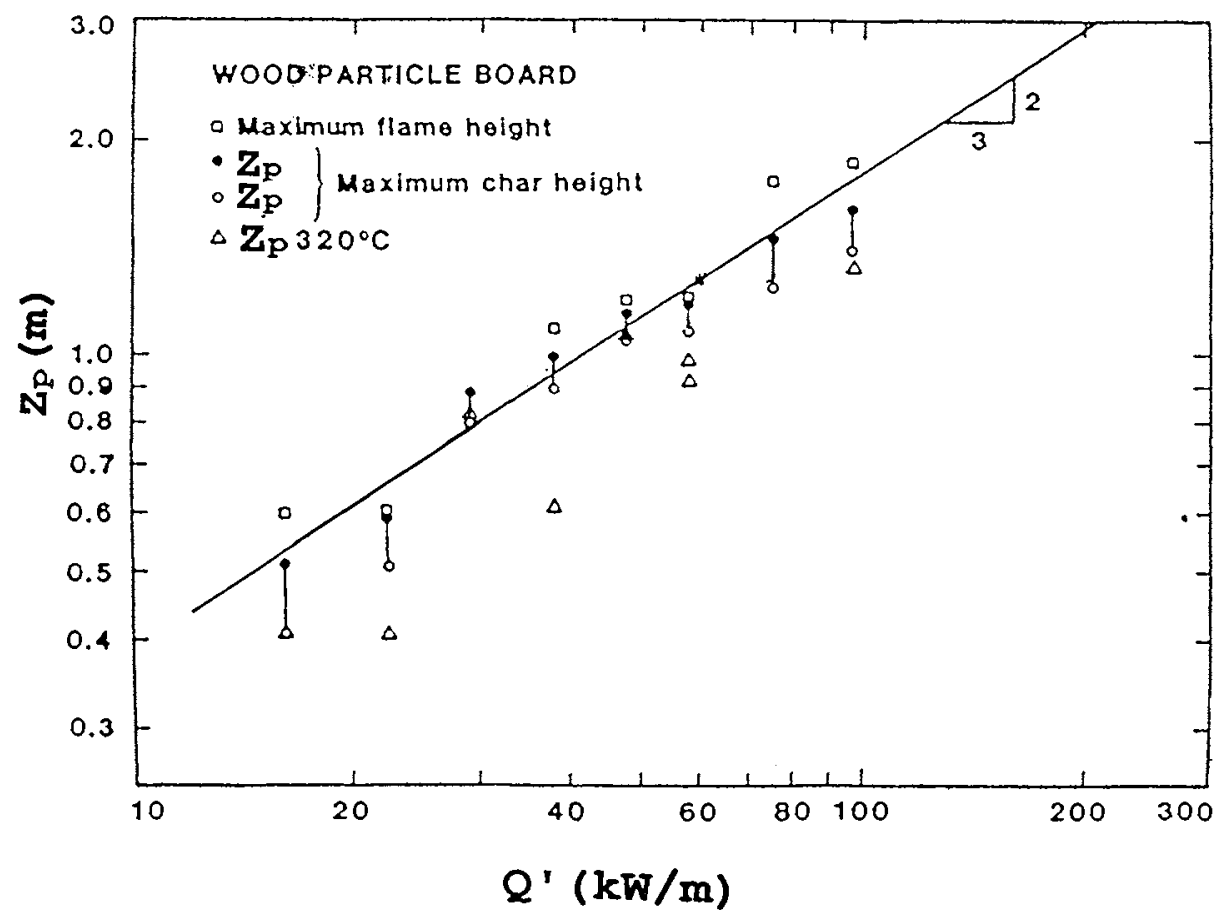

Figure 2 Measured maximum flame height and pyrolysis front in upward flame spread on particle board for varying strength of the line burner at the base of the wall fire. 
According to the authors (Saito et. al. ${ }^{4}$ ), sustained flame spread was not observed for the particle board sample even if the burner was left on for ten minutes. The maximum height of the char (pyrolysis front) increased appreciably with increasing burner energy supply. Figure 2 shows some of the results for the particle board experiments. In addition to the maximum observed flame height, $Z_{F}$, at which spread stops, three different measures of the maximum value of pyrolysis front $Z_{p}$ are shown: 1) $Z_{p}$ based on attaining a surface thermocouple measurement of $320^{\circ} \mathrm{C}$ 2) $Z_{p 1}$, based on observed darkening of wood and 3) $\mathrm{Z}_{\mathrm{p} 2}$ based on a $2 \mathrm{~mm}$ thickness of the char layer.

\section{PREDICTIONS USING THE UPWARD FLAME SPREAD AND GROWTH (UFSG) CODE AND COMPARISON WITH SAITO ${ }^{4}$ DATA}

Having the properties for the (Douglas Fir) particle board as shown in Figure 1, we have applied the FMRC upward flame spread code in order to predict the maximum flame heights measured in Saito's ${ }^{4}$ (see figures) flame spread experiments. As provided by Saito et. al. ${ }^{4}$, we have used a heat of combustion for the particle board $\Delta \mathrm{H}_{\mathrm{c}}=10 \mathrm{~kJ} / \mathrm{g}$.

Additional information for the application of the code is the following:

1. The density of the char layer was taken equal to .2 of the virgin density layer (Parker').

2. Ignition by the line burner at the base of the particle board slab at various energy releases was simulated by a uniform constant distribution of heat flux to the wall over the flame height. The heat flux is ${ }^{1}$ (for $\mathrm{Z}_{\mathrm{p}}<1.5 \mathrm{~m}$ ):

$$
\dot{q}_{f w}^{\prime \prime}=25 \quad \mathrm{~kW} / \mathrm{m}^{2}
$$

and is zero above flame tips. The flame height is:

$$
Z_{f}=.052\left(\dot{Q}_{c h}^{\prime}\right)^{2 / 3}
$$

where $Z_{\mathrm{f}}$ is in $\mathrm{m}$ and $\dot{Q}_{\mathrm{ch}}^{\prime}$ the heat release rate per unit width is in $\mathrm{kW} / \mathrm{m}$. In a new version used only for obtaining results in Figure 6, a distribution of wall heat fluxes has been used which differs from eqn. (1) only for heights $>1.5 \mathrm{~m}$.

3. After pyrolysis of the particle board starts, the flame height is again given by eqn. (1b) wherein the heat release rate is equal to the sum of the heat release rate from the burner and the heat release rate from the pyrolyzing wall. In addition, the heat flux to the wall is again given by eqn. (1a) and it is uniformly distributed over the flame height (see justification in Delichatsios et. al. ${ }^{2}$ ).

4. The particle board is considered thermally thick throughout the process because it is backed by a marinite sheet which can conduct heat.

The results from the flame spread code are shown in Figures 3, 4, and 5. In Figure 3 the location of the pyrolysis front is shown as it varies with time, for four different energy releases from the methane line bumer, and in Figure 4 the flame height is shown. To explain these figures, we follow the flame spread process when the bumer's energy release is $20 \mathrm{~kW} / \mathrm{m}$, which is represented by the solid line in Figures 3 and 4 . 


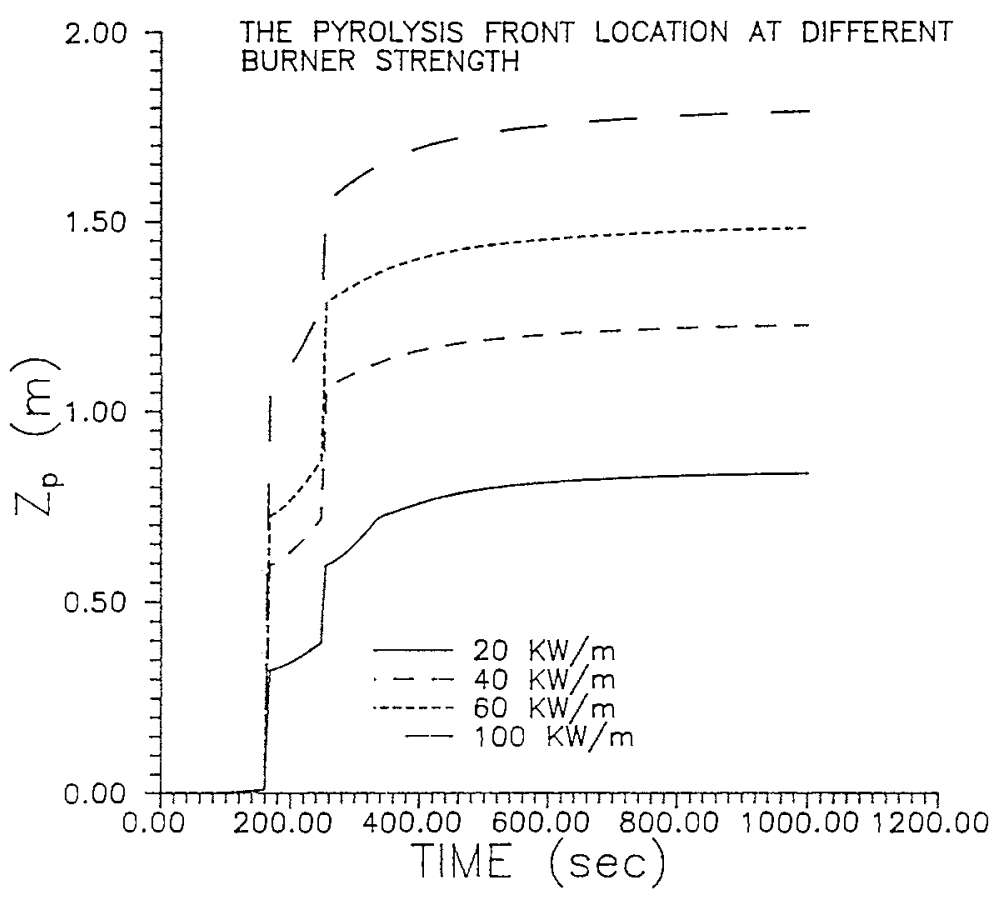

Figure 3 Predictions of upward flame spread histories for particle board: location of pyrolysis front for different burner strength as a function of time.

From Figure 4, one can see that the line burner is applied at $80 \mathrm{~s}$ and its flame height is $Z_{\mathrm{f}}=.052(20)^{2 / 3}=.38 \mathrm{~m}$. The particle board slab is heated over this length with a uniform heat flux of $25 \mathrm{~kW} / \mathrm{m}^{2}$ and ignition of this length follows after about $80 \mathrm{~s}$ (at $160 \mathrm{~s}$ ) as Figure 3 shows. As new material starts pyrolyzing at this time, the wall flame height suddenly increases at $t=160 \mathrm{~s}$ as the solid line in Figure 4 shows. This process repeats again providing the history for the flame height and the pyrolysis front. Flame spread essentially stops when $Z_{p}$ (Figure 3) $=Z_{f}$. In this case, no further preheating of the material ahead of the pyrolysis zone occurs so that flame spread stops (other extinction criteria related to a minimum critical mass flux are not considered here). This maximum value for flame spread on particle board is compared with Saito's results (Figure 2) in Figure 5 for various intensities of the line burner.

It is fair to draw the conclusion from the comparison in Figure 5 that the predictions from the flame spread code, which uses measured properties for the solid particle board material ${ }^{3}$, reproduce the experimental results quite well. 


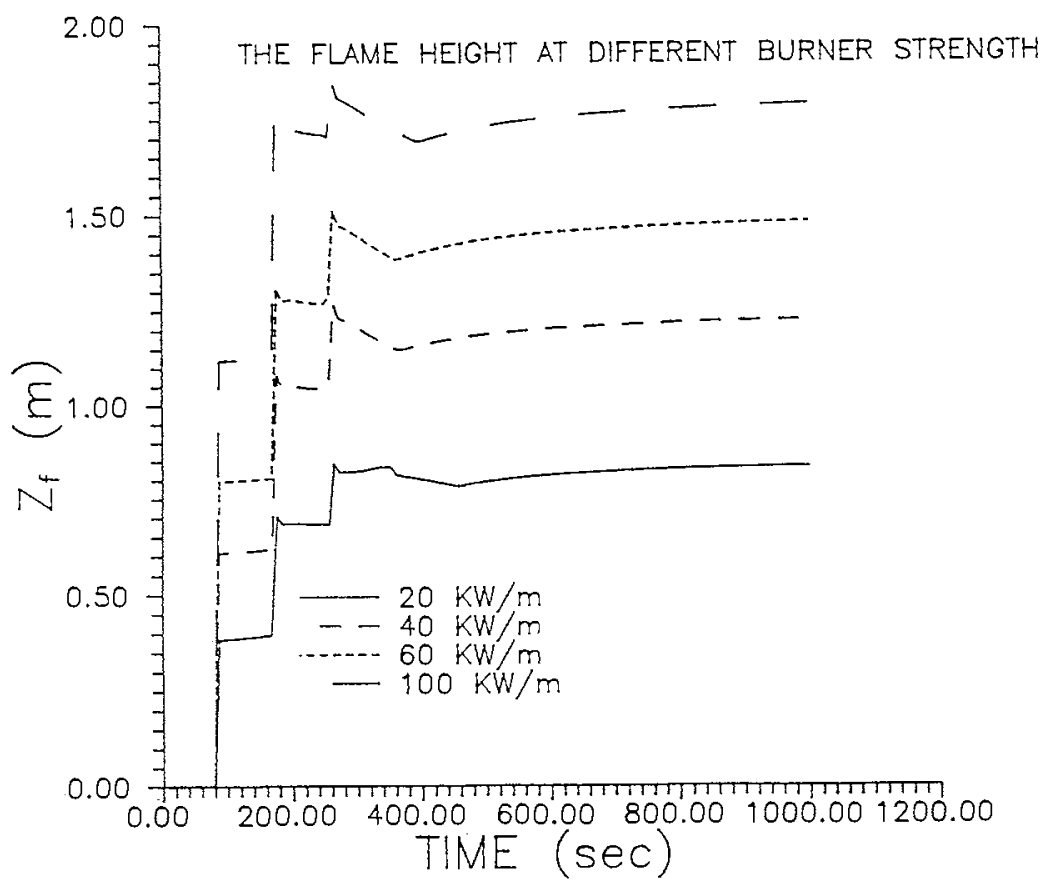

Figure 4 Comparisons of predictions with experiments: maximum flame height (at which spread stops) for different burner strength.

\section{CRITICAL CONDITIONS FOR FLAME SPREAD}

The pyrolysis model for charring materials and the application of the flame spread code make possible validation of critical conditions for upward flame spread which were first developed for non-charring materials ${ }^{2}$. These conditions allow the characterization of maximum flame spread length (cf. Fig. 5) by using an expression which includes the key flammability properties of the charring material.

We first remind the reader that upward flame spread for non-charring materials can be represented by a similarity type expression ${ }^{2}$ for the location of pyrolysis front, $\mathrm{Z}_{\mathrm{p}}$ :

$$
\frac{Z_{p}}{L_{m}}=f C n\left(\frac{t}{t_{p}} \cdot \frac{Z_{p 0}}{L_{m}}\right)
$$

here $Z_{p 0}$ the initial pyrolysis length after ignition, $L_{m}$ is a characteristic flame spread length ${ }^{2}$ defined by: 


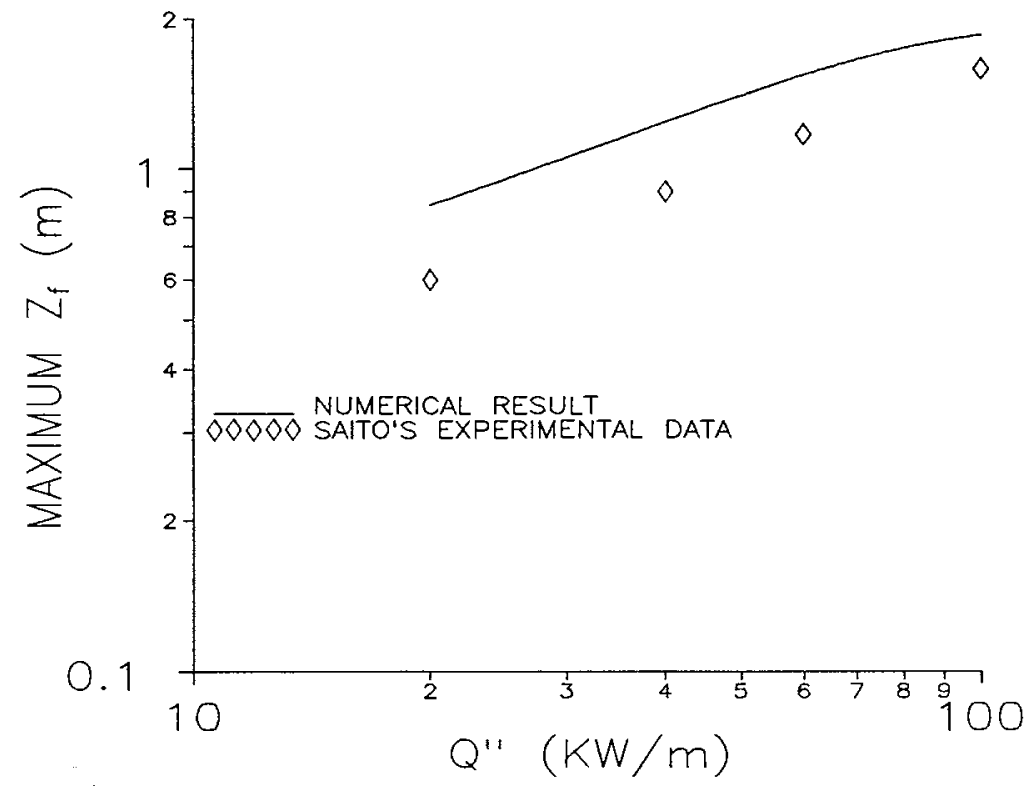

Figure 5 Predictions of upward flame spread histories: flame height histories for different burner strength.

$$
L_{m}=\left(\frac{1}{\rho_{\infty} T_{\infty} C_{g} \sqrt{g}}\right)^{2}\left(\dot{q}_{n \in t}^{\prime \prime} \chi_{A} \frac{\Delta H_{C}}{\Delta H_{v}}\right)^{2}
$$

and $t_{p}$ is a material pyrolysis time defined (approximately) as:

$$
t_{p}=\frac{k p c\left(\Delta T_{p}\right)^{2}}{\phi^{\prime \prime 2}{ }_{n \in t}^{2}}-t_{i g m}
$$

in these expressions:

$\rho_{\infty}, T_{\infty}, c_{z}$ are density, temperature and specific heat of the combustion air, $\mathrm{g}$ is the gravitational acceleration,

$\dot{\mathrm{q}}_{n \mathrm{a}}^{\prime \prime}$ is the net heat flux to the surface from the flames $\dot{\mathrm{q}}_{\mathrm{nat}}^{\prime \prime}=\dot{\mathrm{q}}_{\mathrm{fw}}^{\prime \prime}-\sigma \mathrm{T}_{\mathrm{p}}^{4}$, note also that $\sigma \mathrm{T}_{\mathrm{p}}^{4}=\dot{q}_{\mathrm{cr}}^{\prime \prime}=$ critical imposed heat flux below which no ignition occurs, $\chi_{\mathrm{A}} \Delta \mathrm{H}_{\mathrm{c}}$ is the actual heat of combustion, $\Delta \mathrm{H}_{\mathrm{v}}$ is the heat of gasification (latent plus sensible), $\mathrm{k}, \rho, \mathrm{c}$ are the conductivity, density and specific heat of the (virgin) solid, $\Delta T_{p}=T_{p}-T_{\infty}$ is the surface pyrolysis temperature rise over the ambient value. 
We point out that the total flame heat flux to the wall, $\dot{q}_{\mathrm{fw}}^{\mathrm{n}}$, may be increasing with height but is nearly constant $\left(\simeq 25 \mathrm{~kW} / \mathrm{m}^{2}\right.$ as discussed in previous section) for pyrolysis heights, $Z_{p} \leq 2 \mathrm{~m}$. These results for upward flame spread can be extended to charring materials if the characteristic length, $\mathrm{L}_{\mathrm{m}}$ (eqn. (2b)), is modified to include the effects of the char:

$$
\bar{L}_{m}=\left(\frac{1}{\rho_{-} T_{-} C_{g} \sqrt{g}}\right)^{2}\left(\dot{q}_{n e c}^{\prime \prime} \chi_{A} \frac{\Delta H_{c}}{\Delta H_{v}}\right)^{2} \frac{(1+\lambda) d_{c}}{\delta_{v}}
$$

where the characteristic length scale, $d_{c}$, is defined $\operatorname{as}^{3,5}$ :

$$
d_{c}=\frac{k_{c} T^{*}}{4 \Phi^{\prime \prime}}
$$

and the thermal length $\delta_{\mathrm{v}}$ is defined as:

$$
\delta_{v}=\frac{k_{v}\left(T_{p}-T_{\infty}\right)}{\dot{q}_{n \theta t}^{\prime \prime}}
$$

Moreover, $\lambda$ is the ratio of the latent to sensible heat of pyrolysis, $L$ :

$$
\lambda=\frac{L}{C\left(T_{p}-T_{m}\right)}
$$

$\mathrm{k}_{\mathrm{v}}, \mathrm{k}_{\mathrm{c}}$ are the virgin and char material conductivities and

$$
T^{*}=\left(\frac{q_{f W}^{\prime \prime}}{\sigma}\right)^{1 / 4}
$$

is a maximum surface temperature for which the imposed heat flux is equal to reradiation losses (assuming that the surface emissivity is one).

The modification of the characteristic spread length from the value, $L_{m}$ (eqn. (2b)), for a non-charring materials to the value for charring materials, $\overline{\mathrm{L}}_{\mathrm{m}}$ (eqn. (3a)), was derived from a) an analysis of the charring pyrolysis model (see ref 2,8 ) and b) representation of the upward spread process by the approximate equation ${ }^{2}$ :

$$
\frac{d Z_{p}}{d t}=\frac{Z_{f}-Z_{p}}{t_{p}}
$$

Here, we have used a detailed charring pyrolysis model ${ }^{3}$ and the upward flame spread code ${ }^{1}$ (which does not make use of the approximation in eqn. (4)) to check whether the modified 
length scale, $\overline{\mathrm{L}}_{\mathrm{m}}$, can characterize flame spread on charring materials, namely whether the pyrolysis front can be represented by an expression:

$$
\frac{Z_{p}}{\bar{L}_{m}}=f \operatorname{cn}\left(\frac{t}{t_{p}}, \frac{Z_{p o}}{\bar{L}_{m}}\right)
$$

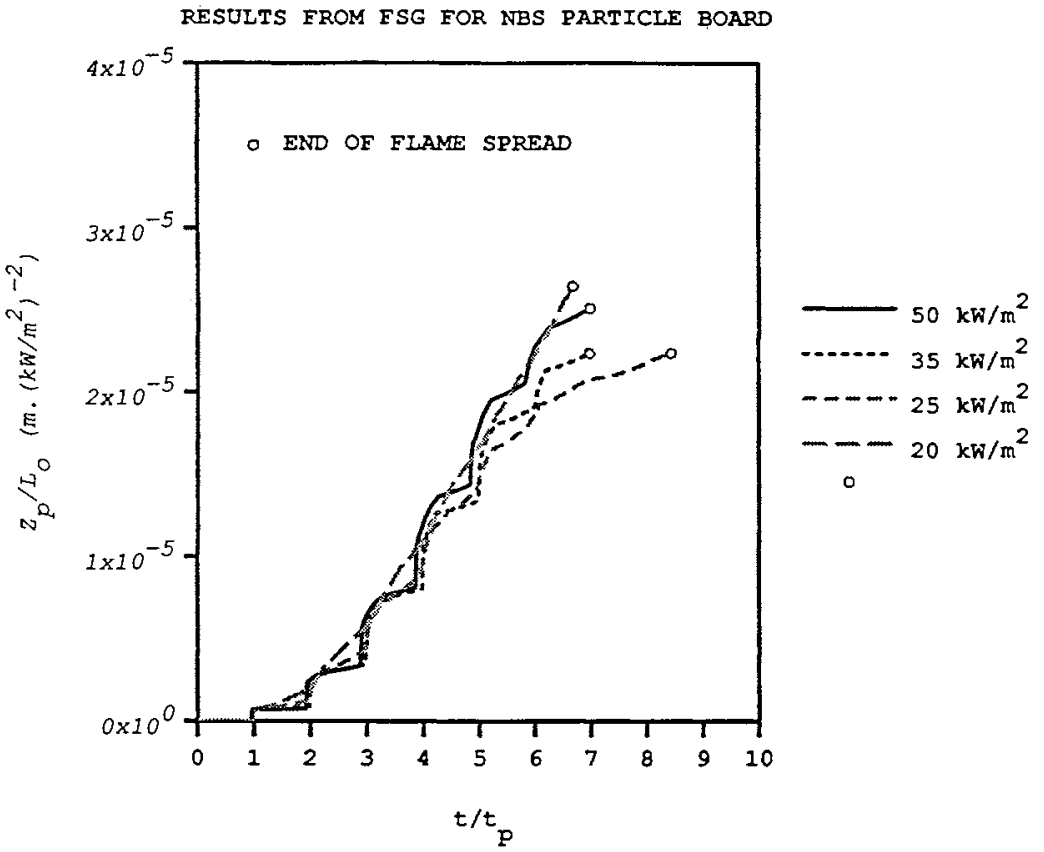

Figure 6 Normalization of the pyrolysis length history, $Z_{p}$ vs. time, using the characteristic length, $\overline{\mathrm{L}}_{0}$ (eqn. (5d)), and pyrolysis time, $\mathrm{t}_{\mathrm{p}}$.

The results of these calculations are shown in Figure 6 which plots the location of pyrolysis length. For these calculation we selected $\mathrm{Z}_{\mathrm{po}}<\mathrm{L}_{\mathrm{m}}$ so that the influence of the initial pyrolysis region is negligible. Flame spread calculations were made for the same material but different flame heat fluxes.

We can make the following remarks concerning Figure 6:

a) Indeed, eqn. (5) is applicable for charring materials,

b) Flame spread stops for charring materials when 
whereas the maximum pyrolysis length is:

$$
\frac{\left(Z_{p}\right)_{\max }}{\overline{L_{0}}} \sim 2 \cdot 10^{-5}
$$

Here, $\mathrm{L}_{0}$ is proportional to $\overline{\mathrm{L}}_{\mathrm{m}}$ (the proportionality constant includes ambient air parameters, eqn. (3a) is neglected):

$$
\vec{L}_{0}=\left(q_{n \theta t}^{\prime \prime} \chi_{A} \frac{\Delta H_{c}}{\Delta H_{v}}\right)^{2} \frac{(1+\lambda) d_{c}}{\delta_{v}}
$$

For the particle board properties shown in Fig. 1 the maximum flame spread length (if the initially pyrolyzing region, $Z_{p 0}$ is small) can be calculated from eqn. (5c) and $(5 \mathrm{~d})$ to be equal to

$$
\left(Z_{p}\right)_{\max }=.47 \mathrm{~m}
$$

assuming that no preheating on the particle board is applied.

We should also point out that in general, the maximum pyrolysis spread length will depend on the initially pyrolyzing region, $\mathrm{Z}_{\mathrm{p} 0}$ :

$$
\frac{z_{p}}{\left(z_{p}\right)_{\max }}=f \operatorname{cn}\left(\frac{z_{p 0}}{\left(z_{p}\right)_{\max }}\right)
$$

It is important to emphasize the following comments: the analysis and the results from the computer code show that the maximum pyrolysis spread length (as given by eqn. $(5 \mathrm{c})$ or in general by eqn. (6)) is independent of the pyrolysis time, $t_{p}$. This time determines, as eqn. (5b) shows, how fast flame spread will reach the critical conditions of maximum flame spread.

\section{COMPARISON WITH OTHER METHODS FOR CRITICAL FLAME SPREAD CONDITIONS}

The basic physics included in the analysis and predictions for the critical flame spread length, $\left(\mathrm{Z}_{\mathrm{p}}\right)_{\max }$, have been examined and validated in detail for each component of the flame spread code ${ }^{1,3}$. The condition for flame spread deceleration and, subsequent stall, occurs when heat fluxes from the flames to the wall ahead of the pyrolysis front are less than the material critical heat flux. This situation is approached as the flame height decreases to 


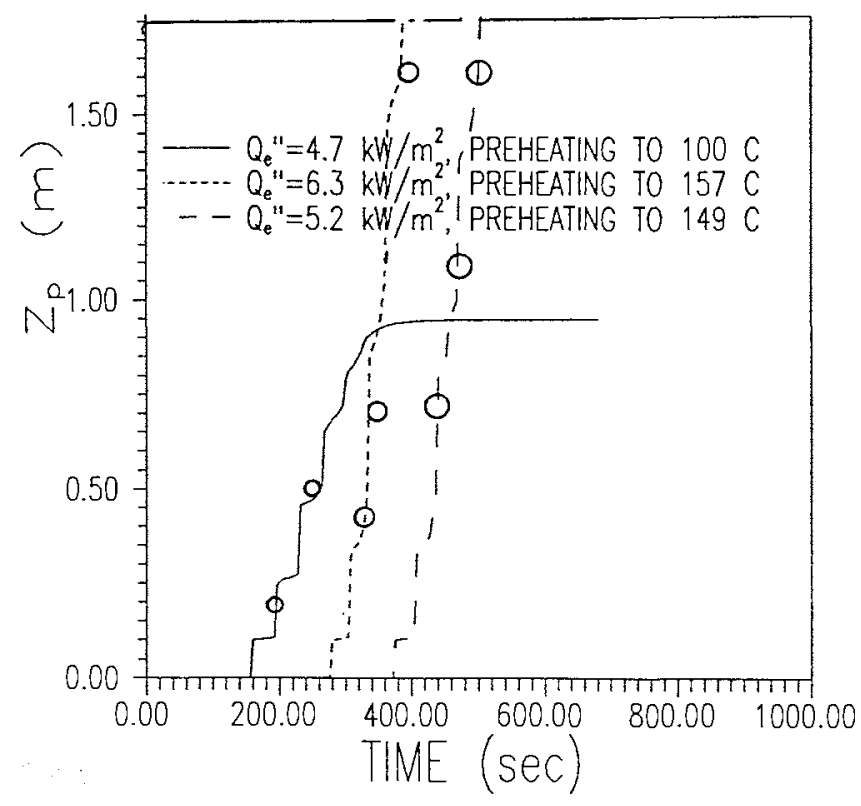

Figure 7 Simulation of flame spread in Hasemi' $\mathrm{s}^{10}$ experiments; continuous lines represent predictions for pyrolysis front, points represent corresponding experimental results obtained from thermocouple measurements.

become nearly equal to the pyrolysis length. The flame height in the upward flame spread simulation is set always to be greater or equal but never smaller than the pyrolyzing length. These flame spread critical conditions have been confirmed by visual observations as briefly discussed in the analysis of Saito et. al. data4.

We also note that the same conditions for the cessation of flame spread have been used in the model developed by Karlson ${ }^{9}$ in Europe. Their final results are quantitatively consistent with the present analysis, even though the details of the approach including the submodels are different. Our methodology is more detailed and the results are well explained and understood from the introduction of the basic physical phenomena and parameters (cf eqn. (2a), (3a)).

Hasemi and Yasui ${ }^{10}$ chose the European analysis for explaining the cessation of flame spread conditions for upward flame spread on particle board ${ }^{10}$. They also kindly provided to us the data for comparison with predictions from our approach and model. Some of the comparisons for upward flame spread on particle board are shown in Fig. 7. In this plot, the pyrolysis front location history, $\mathrm{Z}_{\mathrm{p}}$ is plotted for three different tests wherein different degrees of preheating of the particle board were applied prior to ignition, as illustrated in 
Figure 7. Together with the predictions, we show in Fig. 7 experimental results for the location of the pyrolysis front deduced from temperature measurements by Hasemi ${ }^{10}$ : the pyrolysis front was identified with the location where the temperature first reaches $310^{\circ} \mathrm{C}$. The first point in the experiments was forced to coincide by a time shift with the predictions owing to uncertainties in the ignition process; the other points were placed relative to appropriate time shift. It is important to note that for preheating of $100^{\circ} \mathrm{C}$ no flame spread occurred, as predicted by theory too.

\section{CONCLUSIONS}

The conclusions from the present work are:

1) Upward flame spread on charring materials can be predicted including flame stoppage by using measured flammability properties obtained in a laboratory scale apparatus together with a flame spread code developed earlier ${ }^{1,2}$.

2) The flame spread process on charring materials can be characterized by two sample parameters: a length scale $\overline{\mathrm{L}}_{\mathrm{m}}$ (see eqn. (3a)) and a characteristic pyrolysis time which is also a characteristic spread time $t_{p}$ (see eqn. (2c)). These parameters are derived from the physics of upward flame spread and are similar to the parameters characterizing upward flame spread on non-charring materials.

\section{REFERENCES}

1. Delichatsios, M.M., Mathews, M.K. and Delichatsios, M.A., "An Upward Flame Spread and Growth Simulation", Third Int'1 Symp. on Fire Safety Science, July 1991.

2. Delichatsios, M.A., Chen, Y. and Delichatsios, M.M., "Similarity Solutions for Upward and Wind Assisted Flame Spread and Applications to Non-charring Materials Such as PMMA", ASME Winter Annual Meeting, Anaheim, CA, 1992.

3. Chen, Y., Delichatsios, M.A. and Motevalli, V., "Material Pyrolysis Properties, Part 1: An integral Model for One-dimensional Transient Pyrolysis of Charring and Noncharring Materials", Comb. Sci. Tech., 88, pp. 309-328, 1993.

4. Saito, K., Quintiere, J.G. and Williams, F.A., "Upward Turbulent Flame Spread", First Int'1 Symp. on Fire Safety Science, pp. 75, 1986.

5. Chen, Y., Delichatsios, M.A. and Motevalli, V., "Material Pyrolysis Properties, Part 2: Methodology for Derivation of Pyrolysis Properties for Charring Materials". accepted for publication in Comb. Sci. Tech., Sept. 1993.

6. Delichatsios, M.A., "Burning Polymer Material Properties for Flame Spread", Journal of Fire Sciences, Vol. 11, pp. 2878-295, 1993.

7. Parker, W.J., "Prediction of the Heat Release Rate of Wood", Proceedings of the First Int'l Symp. on Fire Safety Science, pp. 207, 1986.

8. Delichatsios, M.A. and Saito, K., "Upward Flame Spread: Key Flammability Properties, Simulation Solution and Flammability Indices", Third Int'1 Symp. on Fire Safety Science, pp. 217, 1991.

9. Karlson, B., "Modeling Fire Growth on Combustible Lining Materials in Enclosures", Lund University, Dept. Of Fire Safety Engineering, Report TVBB1009, 1992.

10. Hasemi, Y. and Yasui, N., "Upward Flame Spread along a Wooden Wall-Part I", This Conference, 1994. 